\title{
Pregabalin and gabapentin in neuropathic pain management after spinal cord injury: a systematic review and meta-analysis
}

\author{
Majid Davari ${ }^{1}$, Bahman Amani ${ }^{2}$, Behnam Amani $^{2}$, Ahmad Khanijahani $^{3}$, Arash Akbarzadeh ${ }^{4}$, and \\ Rouhollah Shabestan ${ }^{4}$ \\ 'Department of Pharmacoeconomics and Pharmaceutical Administration, Tehran University of Medical Sciences, Tehran, Iran \\ 2Department of Health Management and Economics, School of Public Health, Tehran University of Medical Sciences, Tehran, Iran \\ ${ }^{3}$ Department of Health Administration and Public Health, John G. Rangos School of Health Sciences, Duquesne University, Pittsburgh, PA, USA \\ ${ }^{4}$ Department of Biostatistics and Epidemiology, School of Public Health, Tehran University of Medical Sciences, Tehran, Iran
}

Received July 18, 2019

Revised December 10, 2019

Accepted December 10, 2019

\section{Correspondence}

Bahman Amani

Department of Health Management and Economics, School of Public Health, Tehran University of Medical Sciences, Qods St., Keshavarz Blvd., Tehran 00982113, Iran

Tel: +98-933-308-2779

Fax: +98-21-663-57166

E-mail: B89amani@yahoo.com
Neuropathic pain after spinal cord injury (SCl) has a significant negative impact on the patients' quality of life. The objective of this systematic review is to examine the safety and efficacy of pregabalin (PGB) and gabapentin (GBP) in the treatment of neuropathic pain due to SCl. PubMed, the Cochrane Library, Embase, Scopus, and the Web of Science were searched up to December 2018. The reference lists of key and review studies were reviewed for additional citations. The quality of the studies was evaluated using the Cochrane Collaboration's tools for assessing the risk of bias. A meta-analysis was performed for primary and secondary outcomes. Eight studies were eligible for inclusion. Meta-analysis of PGB vs. placebo showed that PGB was effective for neuropathic pain (standardized mean difference [SMD] $=-0.40 ; 95 \%$ confidence interval $[\mathrm{Cl}]$ : $-0.78,-0.01)$, anxiety $(\mathrm{MD}=-0.68 ; 95 \% \mathrm{Cl}$ : $-0.77,-0.59$ ), depression (mean difference [MD] $=-0.99 ; 95 \% \mathrm{Cl}:-1.08,-0.89$ ), and sleep interference (MD $=-1.08 ; 95 \% \mathrm{Cl}$ : $1.13,-1.02)$. Also, GBP was more effective than a placebo for reducing pain. No significant difference was observed between the efficacy of the two drugs (MD = $-0.37 ; 95 \% \mathrm{Cl}:-1.67,0.93$ ). There was no significant difference between the two drugs for discontinuation due to adverse events (risk ratio $=3.00 ; 95 \% \mathrm{Cl}$ : 0.81, 11.15). PGB and GBP were effective vs. placebos in decreasing neuropathic pain after SCl. Also, there was no significant difference between the two drugs for decreasing pain and adverse events.

Key Words: Anxiety; Depression; Gabapentin; Meta-Analysis; Neuralgia; Pain; Pregabalin; Spinal Cord Injuries; Systematic Review.

\section{INTRODUCTION}

Neuropathic pain is one of the most challenging medical conditions after spinal cord injury (SCI) $[1,2]$, which is associated with anxiety, depression, and sleep disorders [3-5]. It interferes with daily activities and normal functioning $[6,7]$, and has a significant negative impact on the patients' quality of life [7-16]. More than half of those with SCI are estimated to suffer from neuropathic pain [13]. Pharmacological interventions such as anticonvulsant prescriptions have been mainly used to control various types of neuropathic pains [17].

Pregabalin (PGB) and gabapentin (GBP) are recommended as the first-line treatment for neuropathic pain (c) This is an open-access article distributed under the terms of the Creative Commons Attribution Non-Commercial License (http://creativecommons.org/licenses/by-nc/4.0/), which permits unrestricted non-commercial use, distribution, and reproduction in any medium, provided the original work is properly cited.

(c) The Korean Pain Society, 2020
Author contributions: Majid Davari: Supervision; Bahman Amani, Behnam Amani: Methodology; Ahmad Khanijahani: Writing/manuscript preparation; Arash Akbarzadeh: Formal analysis; Rouhollah Shabestan: Investigation. 
due to SCI $[18,19]$. Both drugs have been shown to be effective in the treatment of neuropathic pain due to postherpetic neuralgia [20-26] and diabetic peripheral neuropathy [24-29]. PGB is the new generation of gabapentinoids that acts similar to GBP [30]. PGB is the only medication that is approved by the U.S. Food and Drug Administration for neuropathic pain management in SCI. Many individuals with SCI, regardless of receiving the standard treatments, still suffer from pain [31]. In recent years, several systematic reviews have been published about the efficacy and safety of PGB and GBP in management of neuropathic pain associated with SCI, which almost all compared PGB or GBP with placebos [17,19,32-36]. Lack of evidence for a direct comparison between interventions makes it difficult to choose the most effective treatment [37]. To our knowledge, to date, there is no systematic review comparing PGB and GBP in a head-to-head manner. This systematic review aims to examine the efficacy and safety of PGB and GBP in neuropathic pain management for patients with SCI.

\section{MATERIALS AND METHODS}

The study protocol was registered in international prospective reregister of systematic review (PROSPERO) with the registration number of CRD42019106997. We used the preferred reporting items for systematic reviews and metaanalyses (PRISMA) checklist when writing our report [38].

\section{Literature search}

A systematic review of the relevant literature was conducted in PubMed, the Cochrane Library, Embase, Scopus, and the Web of Science up to December 2018. There were no restrictions on the year or type of publication. The references lists of the selected studies and review articles were reviewed for additional relevant articles. Additionally, to ensure identifying most of the relevant studies, key journals relevant to the topic were searched separately. SCI, neuropathic pain; PGB, and GBP were the search terms.

\section{Study selection}

After removing duplicate records, two authors (ABa and $\mathrm{ABe}$ ) independently reviewed the titles and abstracts of the articles that were included based on the inclusion criteria. Disagreements were resolved by discussion between the two researchers and, if necessary, by a third person (DM). The selected studies were included for analysis if the following criteria were met [21]: (1) the focus was on individuals with neuropathic pain due to SCI with no restriction to any specific age group; (2) PGB and GBP were compared with each other or with a placebo; (3) neuropathic pain was measured as an outcome [22]; (4) the study design was a randomized clinical trial, and [22] (5) was published in the English language. Observational studies, case reports, editorial comments, and studies on animals were excluded.

\section{Data extraction and quality assessments}

We used Cochrane Collaboration's tool to assess the risk of potential bias in the selected studies. The quality of the included randomized controlled trials (RCTs) was assessed independently by two researchers (ABa and AA).

Two reviewers (ABe and RS) independently extracted data using a constructed data extraction form including study characteristics (design, longitude, and following study), participants' characteristics (age, sex, and number of patients), dosage (primarily median and maximum), efficacy outcomes (pain, anxiety, sleep, and depression), and side effects. In case of a dispute, issues were solved by discussion and checking with the third person (MD). The primary efficacy outcome variables were the changes in pain score and secondary outcomes included sleep interference, depression, and anxiety. Safety outcomes, which included adverse events (AEs) and discontinuations, were also analyzed.

\section{Data analysis}

A meta-analysis was performed to compare the efficacy and safety of PGB vs. GBP and PGB vs. placebo. Metaanalysis for the GBP and placebo studies was not possible due to differences in the treatment received by the control group. For example, in one study the control group used a placebo while in another study an active placebo (diphenhydramine) was used. Additionally, in one study, a different scale was used for measuring and reporting the perceived pain. We performed the analysis using RevMan ver. 5.3 software.

For continuous variables, weighted mean difference (MD) and a 95\% confidence interval (CI) were used.

For dichotomous variables, risk ratio (RR) and a 95\% CI were used. Statistical heterogeneity has been evaluated using the $\mathrm{I}^{2}$ and chi-square tests. The random-effects method and the fixed-effect method were used for studies with significant heterogeneity and for those without heterogeneity, respectively. 


\section{RESULTS}

\section{Literature search}

The processes of literature search, removal of duplicates, and screening based on title, abstract, and full text is shown in Fig. 1. The 866 articles found in the initial search were narrowed down to 8 articles that were selected for further eligibility assessment. After checking for all inclusion and exclusion criteria, finally, eight articles [39-46] were included in this review. One head-to-head trial was excluded due to the fact that the type of disease was not specified [47].

\section{Study characteristics}

Of eight studies included in the review, two studies compared PGB with GBP, three studies compared PGB with a placebo, and three studies compared GBP with a placebo. In head-to-head studies [45,46], a total of 58 patients with neuropathic pain due to $\mathrm{SCI}$ in two crossover groups of PGB and GBP entered the studies. Of 58 participants, 40 individuals $(69 \%)$ completed the studies. In both studies $[45,46]$, pain scores were measured by the visual analogue scale (VAS). Sleep quality, depression, and anxiety were secondary outcomes. The prescribed dosage was 150-600 $\mathrm{mg} /$ day, two times per day, for PGB and 300-3,600 mg/day, three times per day for GBP. In three RCTs, 377 patients in two groups (PGB and placebo) were compared with each other $[41,43,44]$. Pain scores were measured by the VAS and duration-adjusted average change. The nine-item medical outcomes study-sleep scale problems index and the hospital anxiety and depression scale were used to measure sleep quality, depression, and anxiety, respectively. In three other RCTs, GBP was compared with a placebo $[39,40,42]$ and an active placebo (diphenhydramine) in patients. The VAS, numeric rating scale, and neuropathic pain scale were used to measure pain scores. In one study, depressive symptomatology was measured by the center for epidemiologic studies depression scale short form. Study characteristics are presented in Table 1 [39-46].

\section{Quality assessment}

Quality assessment of these studies, using the Cochrane Collaboration's tool, is presented in Fig. 2 [39-46].

\section{Efficacy outcomes}

PGB vs. GBP: There is no significant difference between two drugs in the reduction of pain scores $(\mathrm{MD}=-0.37,95 \%$ CI: $-1.67,0.93 ; P>0.05$, Fig. 3) $[45,46]$.

PGB vs. placebo: The meta-analysis demonstrated a significant effect of PGB in comparison to a placebo on the reduction of pain scores (standardized mean difference $[\mathrm{SMD}]=-0.40 ; 95 \% \mathrm{CI}:-0.78,-0.01 ; P<0.05)$. For second-

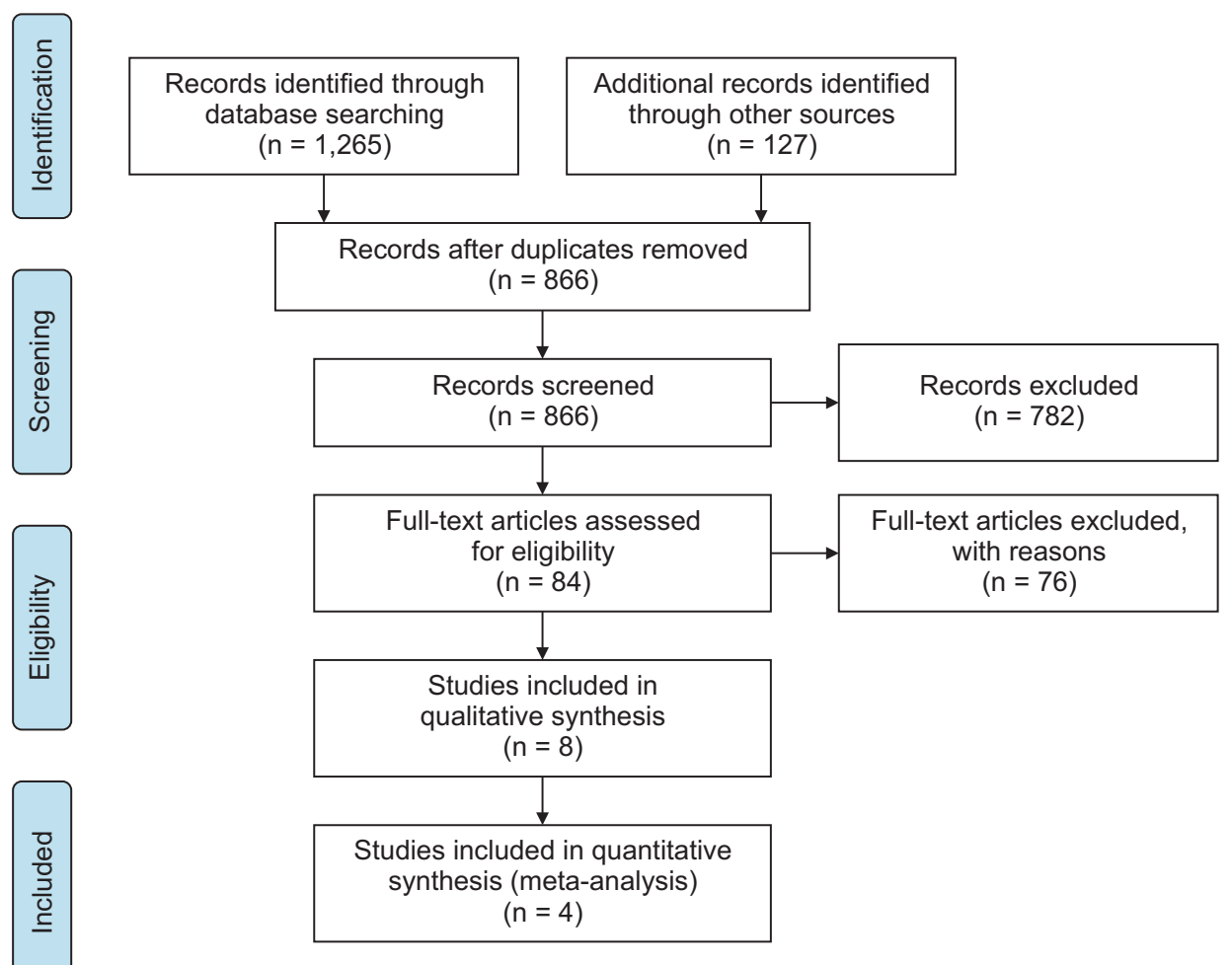

www.epain.org
Fig. 1. Study flow diagram preferred reporting items for systematic reviews and meta-analyses (PRISMA). 
Table 1. Characteristics of the Included Studies

\begin{tabular}{|c|c|c|c|c|c|c|}
\hline Study & Design & Patients & $\begin{array}{l}\text { Intervention/ } \\
\text { Control }\end{array}$ & $\begin{array}{l}\text { Study duration } \\
\text { (wk) }\end{array}$ & Dosage (mg/day) & $\begin{array}{l}\text { Pain measure } \\
\text { scales }\end{array}$ \\
\hline $\begin{array}{l}\text { Cardenas et al. [44] } \\
\text { Chile, China, Columbia, Czech } \\
\text { Republic, Hong Kong, India, Japan, } \\
\text { Philippines, Russian Federation, USA }\end{array}$ & Parallel & $\begin{array}{l}111 \text { PGB, } \\
108 \text { PBO }\end{array}$ & PGB/PBO & 17 & $\begin{array}{l}\text { PGB: } 150-600 \\
\text { PBO: } 150-600\end{array}$ & DAAC \\
\hline $\begin{array}{l}\text { Kaydok et al. [45] } \\
\text { Turkey }\end{array}$ & Crossover & 28 & PGB/GBP & 8 & $\begin{array}{l}\text { PGB: } 150-600 \\
\text { GBP: } 300-3,600\end{array}$ & VAS, NPS \\
\hline $\begin{array}{l}\text { Levendoglu et al. [40] } \\
\text { Turkey }\end{array}$ & Crossover & 20 & GBP/PBO & 20 & $\begin{array}{l}\text { GBP: } 900-3,600 \\
\text { PBO: - }\end{array}$ & VAS, NPS \\
\hline $\begin{array}{l}\text { Rintala et al. [42] } \\
\text { USA }\end{array}$ & Crossover & 38 & GBP/PBO & 8 & $\begin{array}{l}\text { GBP: } 100-1,200 \\
\text { PBO: } 25\end{array}$ & VAS, NRS \\
\hline $\begin{array}{l}\text { Siddall et al. [41] } \\
\text { Australia }\end{array}$ & Parallel & $\begin{array}{l}70 \text { PGB, } \\
67 \text { PBO }\end{array}$ & PGB/PBO & 12 & $\begin{array}{l}\text { PGB: } 150-600 \\
\text { PBO: } 150-600\end{array}$ & VAS \\
\hline $\begin{array}{l}\text { Tai et al. [39] } \\
\text { USA }\end{array}$ & Parallel & 7 & GBP/PBO & 4 & $\begin{array}{l}\text { GBP: } 300-1,800 \\
\text { PBO: } 300-1,800\end{array}$ & NPS \\
\hline $\begin{array}{l}\text { Vranken et al. [43] } \\
\text { Netherlands }\end{array}$ & Parallel & $\begin{array}{l}\text { 11PGB, } \\
10 \text { PBO }\end{array}$ & PGB/PBO & 4 & $\begin{array}{l}\text { PGB: 150-600 } \\
\text { PBO: - }\end{array}$ & VAS \\
\hline $\begin{array}{l}\text { Yilmaz et al. [46] } \\
\text { Turkey }\end{array}$ & Crossover & 21 & PGB/GBP & 16 & $\begin{array}{l}\text { PGB: up to } 300 \\
\text { GBP: up to } 1,800\end{array}$ & VAS \\
\hline
\end{tabular}

PGB: pregabalin, PBO: placebo, DAAC: duration-adjusted average change, GBP: gabapentin, VAS: visual analog scale, NPS: neuropathy pain scale, NRS: numeric rating scale.
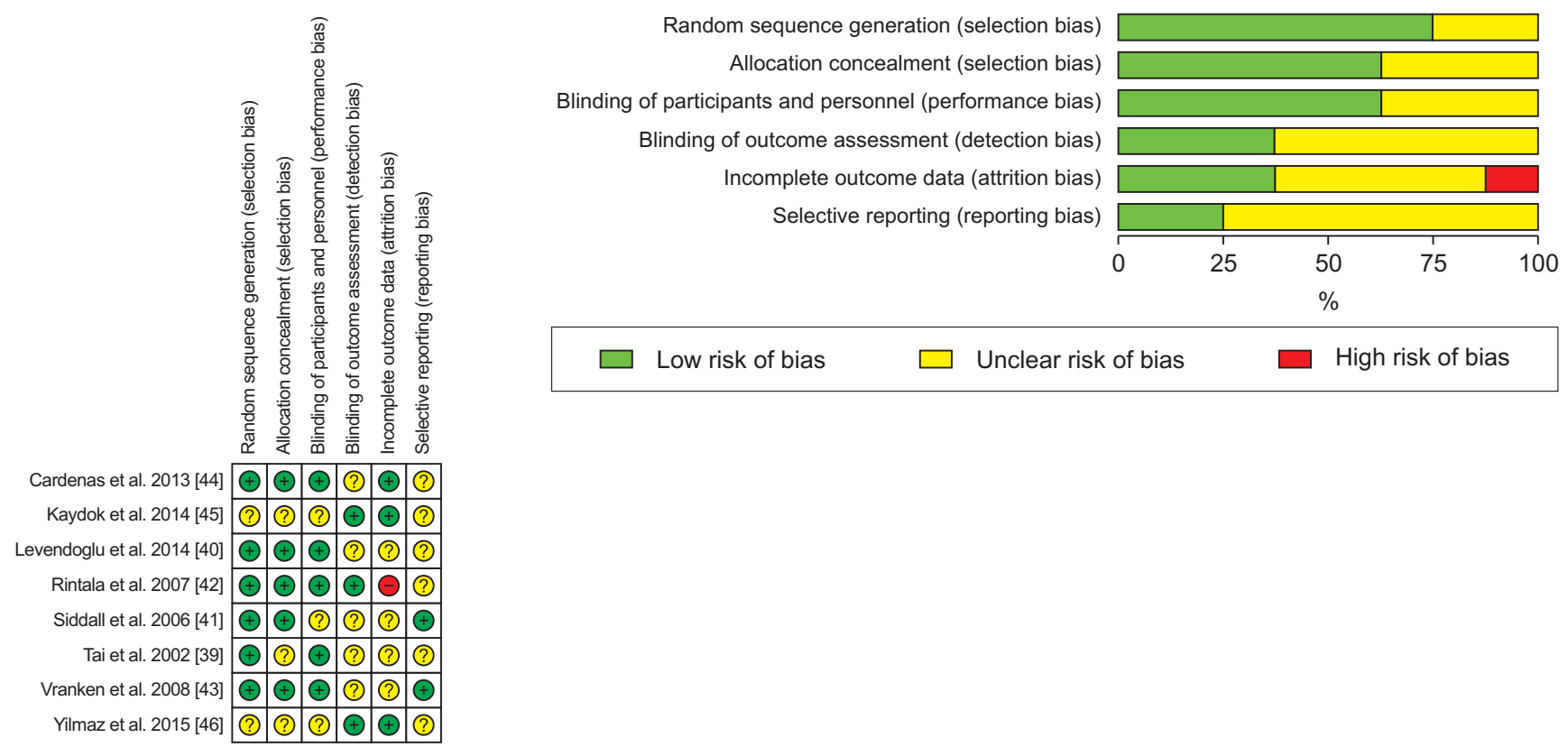

Fig. 2. Risk of bias.

ary outcomes, PGB was more effective than a placebo for anxiety (MD $=-0.68 ; 95 \% \mathrm{CI}:-0.77,-0.59 ; P<0.05)$, depression (MD $=-0.99 ; 95 \% \mathrm{CI}:-1.08,-0.89 ; P<0.05)$, and sleep interference (MD $=-1.08 ; 95 \%$ CI: $-1.13,-1.02 ; P<0.05$, Fig. 4) $[41,44]$.

GBP vs. placebo: In two studies [39,40,42], GBP was only effective in some aspects of neuropathic pain such as pain intensity, unpleasantness, and hot sensation. In one study [42], there was no significant difference between GBP and an active placebo (diphenhydramine) in terms of pain scores. Generally, GBP vs. a placebo was more effective. 


\begin{tabular}{|c|c|c|c|c|c|c|c|c|c|}
\hline Study or Subgroup & Mean & $\begin{array}{l}\text { PGB } \\
\text { SD }\end{array}$ & Total & Mean & $\begin{array}{l}\text { GBP } \\
\text { SD }\end{array}$ & Total & Weight & $\begin{array}{c}\text { MD } \\
\text { IV, fixed, } 95 \% \mathrm{Cl}\end{array}$ & $\begin{array}{c}\text { MD } \\
\text { IV, fixed, } 95 \% \mathrm{Cl}\end{array}$ \\
\hline $\begin{array}{l}\text { Kaydok et al. } 2014 \text { [45] } \\
\text { Yilmaz et al. } 2015 \text { [46] }\end{array}$ & $\begin{array}{l}-4.4 \\
-3.2\end{array}$ & $\begin{array}{r}1.71 \\
3.9\end{array}$ & $\begin{array}{l}11 \\
13\end{array}$ & $\begin{array}{l}-4.21 \\
-2.25\end{array}$ & $\begin{array}{l}1.75 \\
3.21\end{array}$ & $\begin{array}{l}10 \\
15\end{array}$ & $\begin{array}{l}76.4 \% \\
23.6 \%\end{array}$ & $\begin{array}{l}-0.19[-1.67,1.29] \\
-0.95[-3.62,1.72]\end{array}$ & \\
\hline Total $(95 \% \mathrm{Cl})$ & & & 24 & & & 25 & $100.0 \%$ & $-0.37[-1.67,0.93]$ & \\
\hline \multicolumn{10}{|c|}{ 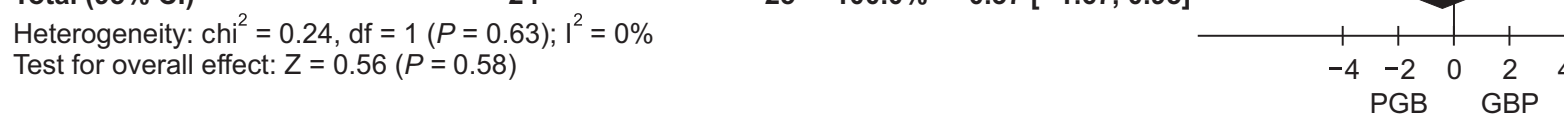 } \\
\hline
\end{tabular}

Fig. 3. Pooled mean difference (MD) of pregabalin (PGB) vs. gabapentin (GBP) for pain outcome. There was no significant difference between two drugs for reducing pain. SD: standard deviation, $\mathrm{Cl}$ : confidence interval, df: degree of freedom.

A. Pain

PGB PBO Standardized MD Study or Subgroup Mean SD Total Mean SD Total Weight IV, random, $95 \% \mathrm{CI}$

\begin{tabular}{lllllllll}
\hline Cardenas et al. 2013 [44] & -1.92 & 4.2 & 105 & -1.22 & 1.96 & 106 & $53.7 \%$ & $-0.21[-0.48,0.06]$
\end{tabular}

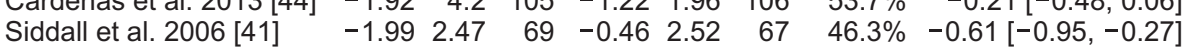

Total $(95 \% \mathrm{Cl}) \quad 174 \quad 173 \quad 100.0 \%-0.40[-0.78,-0.01]$ Heterogeneity: Tau $^{2}=0.05 ;$ chi $^{2}=3.15, \mathrm{df}=1(P=0.08) ; I^{2}=68 \%$ Test for overall effect: $Z=2.01(P=0.04)$

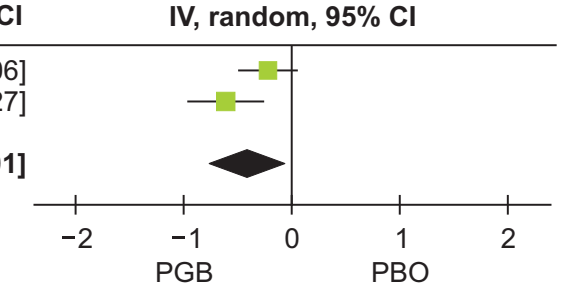

B. Anxiety

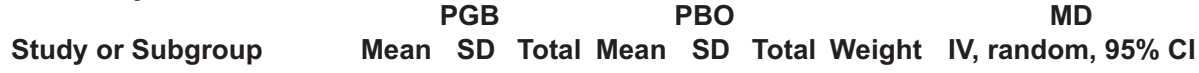

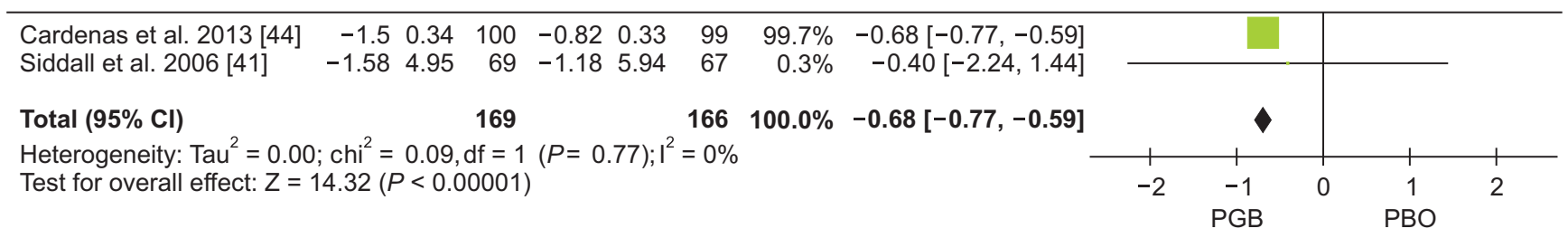

C. Depression

$\begin{array}{lccc} & \text { PGB } & \text { PBO } & \text { MD } \\ \text { Study or Subgroup } & \text { Mean } & \text { SD } & \text { Total Mean } \\ & \text { SD } & \text { Total Weight } & \text { IV, fixed, } 95 \% \mathrm{Cl}\end{array}$

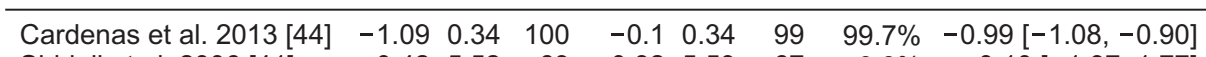

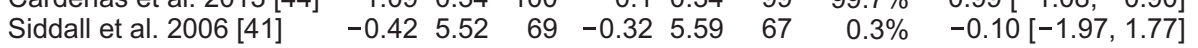

Total $(95 \% \mathrm{Cl})$

169

Heterogeneity: $\mathrm{chi}^{2}=0.87, \mathrm{df}=1(P=0.35) ; \mathrm{I}^{2}=0 \%$

Test for overall effect: $Z=20.52(P<0.00001)$

$166 \quad 100.0 \%-0.99[-1.08,-0.89]$

D. Sleep interference

$\begin{array}{lccc} & \text { PGB } & \text { PBO } & \text { MD } \\ \text { Study or Subgroup } & \text { Mean } & \text { SD } & \text { Total Mean } \\ \text { SD } & \text { Total Weight } & \text { IV, fixed, } 95 \% \mathrm{CI}\end{array}$

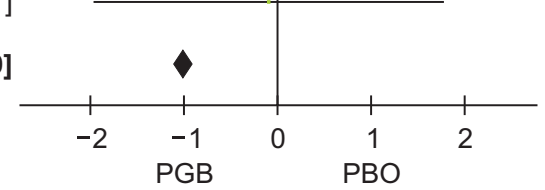

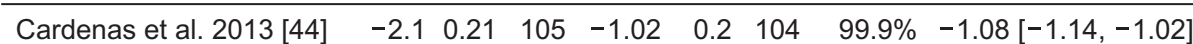

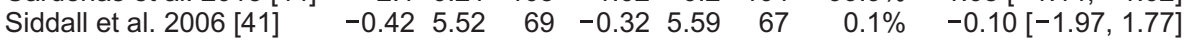

Total $(95 \% \mathrm{Cl})$

174

Heterogeneity: $\mathrm{chi}^{2}=1.06, \mathrm{df}=1(P=0.30) ; I^{2}=5 \%$

Test for overall effect: $Z=38.06(P<0.00001)$

$171 \quad 100.0 \%-1.08[-1.13,-1.02]$

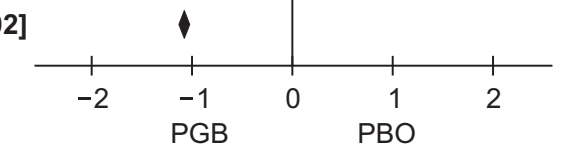

Fig. 4. Pooled mean difference (MD) of pregabalin (PGB) vs. placebo (PBO) for outcomes of pain (A), anxiety (B), depression (C), and sleep interference (D). PGB is effective vs. PBO for all outcomes. SD: standard deviation, Cl: confidence interval, df: degree of freedom.

\section{Safety outcomes}

PGB vs. GBP: Drowsiness and somnolence were the commonly reported AEs for PGB and GBP $[45,46]$. Patients in the PGB group experienced a greater number of AEs than in the GBP group. Seven patients in the PGB group and two patients in the GBP group had to discontinue their medication therapy due to AEs. No significant difference was 


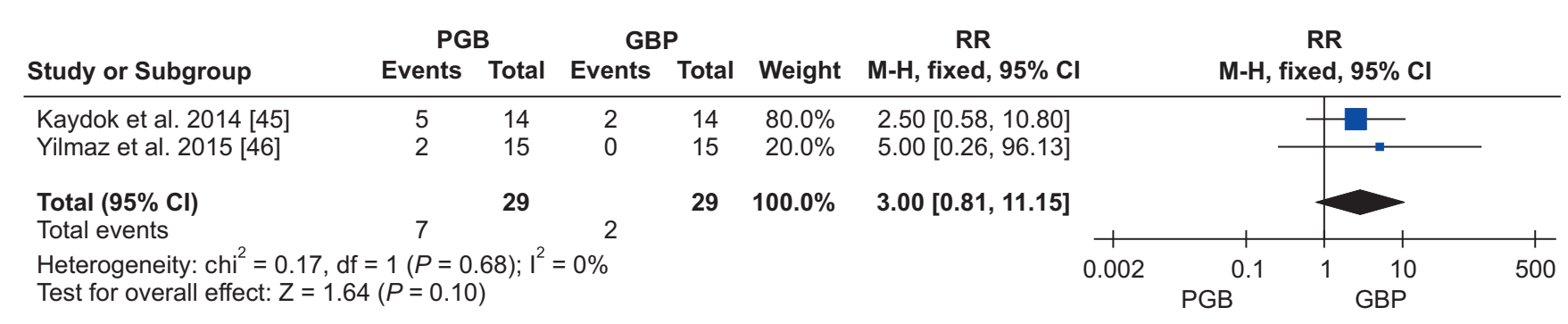

Fig. 5. Pooled risk ratio (RR) of pregabalin (PGB) vs. gabapentin (GBP) for adverse events (AEs). There was no significant difference between two drugs for AEs. Cl: confidence interval, df: degree of freedom.

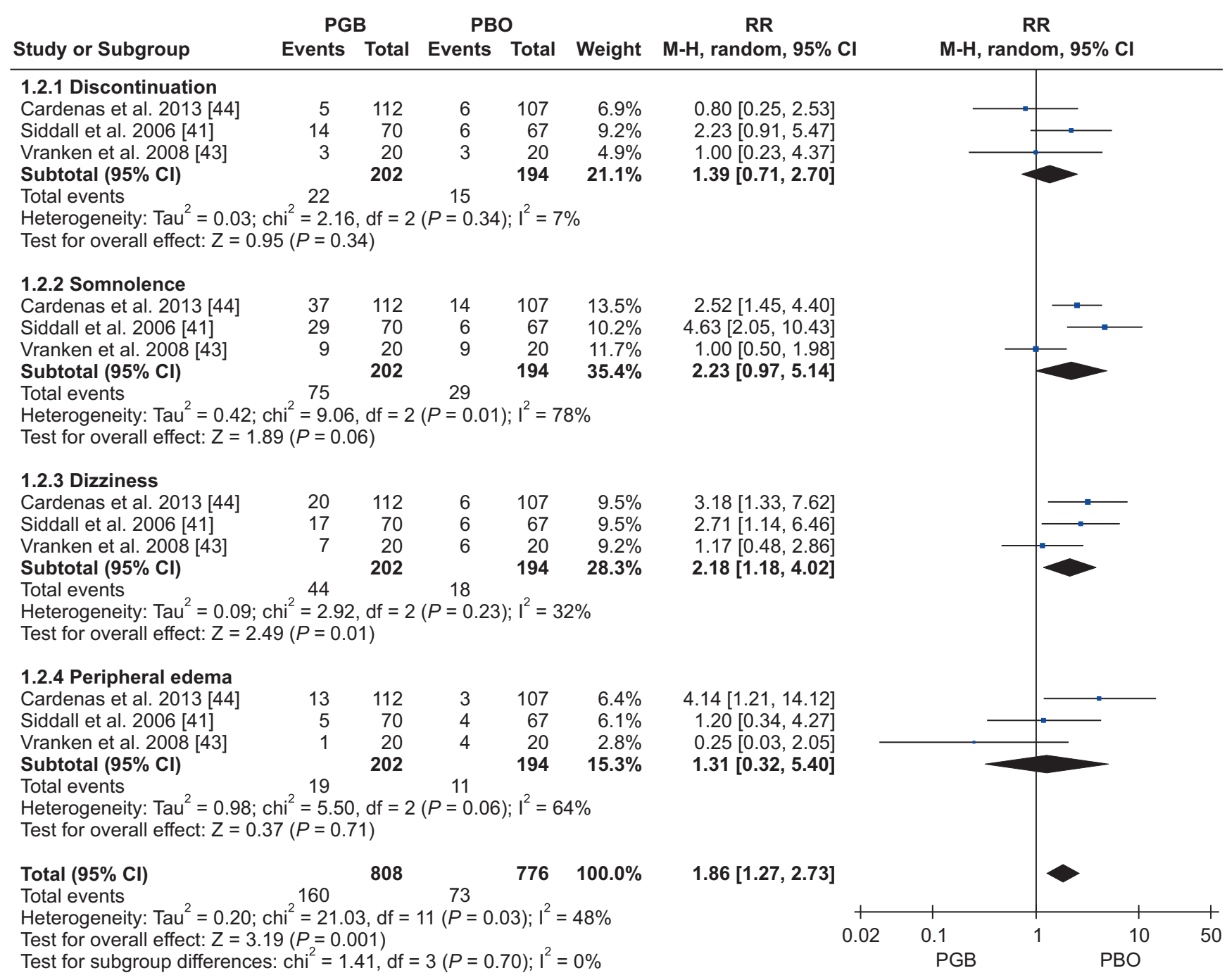

Fig. 6. Pooled risk ratio (RR) of pregabalin (PGB) vs. placebo (PBO) for adverse events. There was no significant difference between PGB and PBO for discontinuation, somnolence, and peripheral edema. The incidence of dizziness was higher for PGB. Cl: confidence interval, df: degree of freedom.

observed in discontinuation due to AEs in the two treatment groups (RR = 3.00; 95\% CI: 0.81, 11.15; $P>0.05$, Fig. 5) $[45,46]$.

PGB vs. placebo: Drowsiness, dizziness, edema, and peripheral edema were the most common AEs in the selected studies $[41,43,44]$. According to the analyses performed on the results reported by the studies, no significant dif- ference was observed between PGB and the placebo for discontinuation due to AEs (RR = 1.39; 95\% CI: 0.71, 2.70; $P$ $>0.05)$, somnolence ( $\mathrm{RR}=2.23 ; 95 \% \mathrm{CI}: 0.97,5.14 ; P>0.05)$, and peripheral edema $(\mathrm{RR}=1.31 ; 95 \% \mathrm{CI}: 0.32,5.40 ; P>$ 0.05). However, there was a significant difference between PGB and the placebo for dizziness ( $R R=2.23$; 95\% CI: 0.97, 5.14; $P<0.05$, Fig. 6) $[41,43,44]$. GBP vs. a placebo: The most 
common AEs reported for GBP were dry mouth, drowsiness, fatigue, dizziness, constipation, edema, and vertigo $[39,40,42]$. Nonetheless, one of the selected studies showed no significant difference in AEs between the recipients of GBP and the placebo $[39,40,42]$.

\section{DISCUSSION}

The purpose of this systematic review was to examine the safety and efficacy of PGB and GBP in the treatment of neuropathic pain due to SCI. This study is the first systematic review and meta-analysis in which the two drugs have been compared directly with each other. A systematic review of head-to-head trails provides the highest quality evidence to compare the effectiveness of the two interventions [48].

In recent years, several recommendations have been published considering the efficacy and safety of PGB and GBP in the management of neuropathic pain after SCI $[17,19,32-36,49]$. To our knowledge, these recommendations $[17,19,32-36,49]$ were limited to randomized placebocontrolled trials only and, due to the lack of head-to-head studies, had important limitations. Recently, A limited number of studies performed head-to-head comparison of these drugs and the results of these studies showed that both drugs were effective in the treatment of neuropathic pain $[45,46]$.

The results of our meta-analysis showed that both PGB and GBP have similar efficacy in reducing pain, and there was no significant difference between the two interventions. In previous systematic reviews [17,19,32-36,49], both drugs were found to be effective in reducing neuropathic pain due to SCI, which is similar to the findings of the present study. However, studies included in these reviews did not compare PGB and GBP with each other [39-44,5052].

In several systematic reviews $[17,35,36]$, no significant difference was reported between the efficacy of PGB and GBP in individuals with SCI, which, from the statistical point of view, is similar to the findings of our study. On the other hand, evidence shows that results of indirect comparisons are usually in accordance with the results of direct comparisons [53]. The findings of the current study vary from several other review studies [32-34] which compared PGB and GBP with a placebo. In those studies, it was concluded that PGB is more effective than GBP in the treatment of neuropathic pain due to SCI. These differences can be attributed to the lack of head-to-head trials in those studies.

In a meta-analysis conducted by Mehta et al. [36], lack of a direct comparison between PGB and GBP was con- sidered a barrier to making a conclusive statement about difference in efficacy (decreasing neuropathic pain after SCI) of the two drugs, but such limitations did not exist in the present study. Ghosh et al. [47] studied the efficacy and safety of PGB and GBP in 100 patients with neuropathic pain in a head-to-head design using an unclear indication. At the end of the study, consistent with our findings, VAS pain scores were similar in the PGB and GBP groups, and both drugs lead to a decrease in neuropathic pain. But PGB showed better results in comparison to GBP based on the pain quality assessment scale.

The findings of this meta-analysis showed that PGB, compared to a placebo, was more effective in reducing neuropathic pain, sleep disorders, anxiety, and depression, while, GBP vs. a placebo, was shown to be effective in some aspects of pain.

Drowsiness and somnolence were the most reported side effects of PGB and GBP in crossover studies $[45,46]$. The number of adverse events and discontinuations due to treatment were higher for PGB in comparison to GBP. Our meta-analysis showed that dizziness was a side effect of PGB in comparison with a placebo. However, the results of a study [54] showed the long-term safety and tolerability of PGB in patients with central neuropathic pain due to SCI. Results of a systematic review by Tzellos et al. [32] indicated that PGB had greater side effects in comparison to GBP.

The poor methodological quality of the head-to-head studies, small sample sizes, and lack of enough data limited our ability to perform further in-depth meta-analysis on findings of the previous studies. Restriction of the reviewed studies to the English language was another limitation of this study. However, expanding the inclusion criteria to the studies with English abstracts increased the pool of the potential studies to be chosen for further analyses.

The findings of this study suggest that both PGB and GBP are effective in the treatment of neuropathic pain associated with SCI. Likewise, head-to-head studies showed that there was no significant difference between the two drugs in reducing pain scores. Similarly, there was no significant difference in the safety profiles of the two drugs. We suggest a network meta-analysis for future studies.

\section{CONFLICT OF INTEREST}

No potential conflict of interest relevant to this article was reported. 


\section{FUNDING}

No funding to declare.

\section{ORCID}

Majid Davari, https://orcid.org/0000-0001-7483-0259

Bahman Amani, https://orcid.org/0000-0002-2340-189X

Behnam Amani, https://orcid.org/0000-0003-4298-1807

Ahmad Khanijahani, https://orcid.org/0000-0002-0172-9421

Arash Akbarzadeh, https://orcid.org/0000-0002-4881-544X

Rouhollah Shabestan, https://orcid.org/0000-0003-4809-5662

\section{REFERENCES}

1. Kamble SV, Motlekar SA, D'souza LL, Kudrigikar VN, Rao SE. Low doses of amitriptyline, pregabalin, and gabapentin are preferred for management of neuropathic pain in India: is there a need for revisiting dosing recommendations? Korean J Pain 2017; 30: 183-91.

2. Werhagen L, Budh CN, Hultling C, Molander C. Neuropathic pain after traumatic spinal cord injury--relations to gender, spinal level, completeness, and age at the time of injury. Spinal Cord 2004; 42: 665-73.

3. Castro MM, Daltro C. Sleep patterns and symptoms of anxiety and depression in patients with chronic pain. Arq Neuropsiquiatr 2009; 67: 25-8.

4. Gore M, Brandenburg NA, Dukes E, Hoffman DL, Tai KS, Stacey B. Pain severity in diabetic peripheral neuropathy is associated with patient functioning, symptom levels of anxiety and depression, and sleep. J Pain Symptom Manage 2005; 30: 374-85.

5. Gormsen L, Rosenberg R, Bach FW, Jensen TS. Depression, anxiety, health-related quality of life and pain in patients with chronic fibromyalgia and neuropathic pain. Eur J Pain 2010; 14: 127.el-8.

6. McDermott AM, Toelle TR, Rowbotham DJ, Schaefer CP, Dukes EM. The burden of neuropathic pain: results from a cross-sectional survey. Eur J Pain 2006; 10: 127-35.

7. Gustorff B, Dorner T, Likar R, Grisold W, Lawrence K, Schwarz F, et al. Prevalence of self-reported neuropathic pain and impact on quality of life: a prospective representative survey. Acta Anaesthesiol Scand 2008; 52: 132-6.

8. Hassanijirdehi M, Khak M, Afshari-Mirak S, HolakouieNaieni K, Saadat S, Taheri T, et al. Evaluation of pain and its effect on quality of life and functioning in men with spinal cord injury. Korean J Pain 2015; 28: 129-36.

9. Lude P, Kennedy P, Elfström ML, Ballert CS. Quality of life in and after spinal cord injury rehabilitation: a longitudinal multicenter study. Top Spinal Cord Inj Rehabil 2014; 20: 197-
207.

10. Dermanovic Dobrota V, Hrabac P, Skegro D, Smiljanic R, Dobrota S, Prkacin I, et al. The impact of neuropathic pain and other comorbidities on the quality of life in patients with diabetes. Health Qual Life Outcomes 2014; 12: 171.

11. Geyh S, Ballert C, Sinnott A, Charlifue S, Catz A, D'Andrea Greve JM, et al. Quality of life after spinal cord injury: a comparison across six countries. Spinal Cord 2013; 51: 322-6.

12. Leem YJ, Joh JW, Joeng KW, Suh JH, Shin JW, Leem JG. Central pain from excitotoxic spinal cord injury induced by intraspinal NMDA injection: a pilot study. Korean J Pain 2010; 23: 109-15.

13. Wollaars MM, Post MW, van Asbeck FW, Brand N. Spinal cord injury pain: the influence of psychologic factors and impact on quality of life. Clin J Pain 2007; 23: 383-91.

14. Smith BH, Torrance N, Bennett MI, Lee AJ. Health and quality of life associated with chronic pain of predominantly neuropathic origin in the community. Clin J Pain 2007; 23: 143-9.

15. Gálvez R, Marsal C, Vidal J, Ruiz M, Rejas J. Cross-sectional evaluation of patient functioning and health-related quality of life in patients with neuropathic pain under standard care conditions. Eur J Pain 2007; 11: 244-55.

16. Davies M, Brophy S, Williams R, Taylor A. The prevalence, severity, and impact of painful diabetic peripheral neuropathy in type 2 diabetes. Diabetes Care 2006; 29: 1518-22.

17. Teasell RW, Mehta S, Aubut JA, Foulon B, Wolfe DL, Hsieh JT, et al.; Spinal Cord Injury Rehabilitation Evidence Research Team. A systematic review of pharmacologic treatments of pain after spinal cord injury. Arch Phys Med Rehabil 2010; 91: 816-31.

18. DeFrates S, Cook AM. Pharmacologic treatment of neuropathic pain following spinal cord injury. Orthopedics 2011; 34: 203.

19. Hagen EM, Rekand T. Management of neuropathic pain associated with spinal cord injury. Pain Ther 2015; 4: 51-65.

20. Rowbotham M, Harden N, Stacey B, Bernstein P, MagnusMiller L. Gabapentin for the treatment of postherpetic neuralgia: a randomized controlled trial. JAMA 1998; 280: 183742.

21. Rice AS, Maton S; Postherpetic Neuralgia Study Group. Gabapentin in postherpetic neuralgia: a randomised, double blind, placebo controlled study. Pain 2001; 94: 215-24.

22. Sabatowski R, Gálvez R, Cherry DA, Jacquot F, Vincent E, Maisonobe P, et al.; 1008-045 Study Group. Pregabalin reduces pain and improves sleep and mood disturbances in patients with post-herpetic neuralgia: results of a randomised, placebo-controlled clinical trial. Pain 2004; 109: 26-35.

23. van Seventer R, Feister HA, Young JP Jr, Stoker M, Versavel M, Rigaudy L. Efficacy and tolerability of twice-daily pregabalin for treating pain and related sleep interference in postherpetic neuralgia: a 13-week, randomized trial. Curr Med Res 
Opin 2006; 22: 375-84.

24. Moon DE, Lee DI, Lee SC, Song SO, Yoon DM, Yoon MH, et al. Efficacy and tolerability of pregabalin using a flexible, optimized dose schedule in Korean patients with peripheral neuropathic pain: a 10-week, randomized, double-blind, placebo-controlled, multicenter study. Clin Ther 2010; 32: 2370-85.

25. Xochilcal-Morales M, Castro EM, Guajardo-Rosas J, Obregón TN, Acevedo JC, Chucan JM, et al. A prospective, open-label, multicentre study of pregabalin in the treatment of neuropathic pain in Latin America. Int J Clin Pract 2010; 64: 1301-9.

26. Guan Y, Ding X, Cheng Y, Fan D, Tan L, Wang Y, et al. Efficacy of pregabalin for peripheral neuropathic pain: results of an 8-week, flexible-dose, double-blind, placebo-controlled study conducted in China. Clin Ther 2011; 33: 159-66.

27. Backonja M, Beydoun A, Edwards KR, Schwartz SL, Fonseca V, Hes M, et al. Gabapentin for the symptomatic treatment of painful neuropathy in patients with diabetes mellitus: a randomized controlled trial. JAMA 1998; 280: 1831-6.

28. Sandercock D, Cramer M, Wu J, Chiang YK, Biton V, Heritier M. Gabapentin extended release for the treatment of painful diabetic peripheral neuropathy: efficacy and tolerability in a double-blind, randomized, controlled clinical trial. Diabetes Care 2009; 32: e20.

29. Tölle T, Freynhagen R, Versavel M, Trostmann U, Young JP Jr. Pregabalin for relief of neuropathic pain associated with diabetic neuropathy: a randomized, double-blind study. Eur J Pain 2008; 12: 203-13.

30. Guay DR. Pregabalin in neuropathic pain: a more "pharmaceutically elegant" gabapentin? Am J Geriatr Pharmacother 2005; 3: 274-87.

31. Turner JA, Cardenas DD, Warms CA, McClellan CB. Chronic pain associated with spinal cord injuries: a community survey. Arch Phys Med Rehabil 2001; 82: 501-9.

32. Tzellos TG, Papazisis G, Amaniti E, Kouvelas D. Efficacy of pregabalin and gabapentin for neuropathic pain in spinalcord injury: an evidence-based evaluation of the literature. Eur J Clin Pharmacol 2008; 64: 851-8.

33. Attal N, Mazaltarine G, Perrouin-Verbe B, Albert T; SOFMER French Society for Physical Medicine and Rehabilitation. Chronic neuropathic pain management in spinal cord injury patients. What is the efficacy of pharmacological treatments with a general mode of administration? (oral, transdermal, intravenous). Ann Phys Rehabil Med 2009; 52: 124-41.

34. Snedecor SJ, Sudharshan L, Cappelleri JC, Sadosky A, Desai $\mathrm{P}$, Jalundhwala YJ, et al. Systematic review and comparison of pharmacologic therapies for neuropathic pain associated with spinal cord injury. J Pain Res 2013; 6: 539-47.

35. Guy S, Mehta S, Leff L, Teasell R, Loh E. Anticonvulsant medication use for the management of pain following spinal cord injury: systematic review and effectiveness analysis. Spinal Cord 2014; 52: 89-96.
36. Mehta S, McIntyre A, Dijkers M, Loh E, Teasell RW. Gabapentinoids are effective in decreasing neuropathic pain and other secondary outcomes after spinal cord injury: a metaanalysis. Arch Phys Med Rehabil 2014; 95: 2180-6.

37. Song F, Altman DG, Glenny AM, Deeks JJ. Validity of indirect comparison for estimating efficacy of competing interventions: empirical evidence from published meta-analyses. BMJ 2003; 326: 472.

38. Moher D, Liberati A, Tetzlaff J, Altman DG; PRISMA Group. Preferred reporting items for systematic reviews and metaanalyses: the PRISMA statement. Ann Intern Med 2009; 151: 264-9.

39. Tai Q, Kirshblum S, Chen B, Millis S, Johnston M, DeLisa JA. Gabapentin in the treatment of neuropathic pain after spinal cord injury: a prospective, randomized, double-blind, crossover trial. J Spinal Cord Med 2002; 25: 100-5.

40. Levendoglu F, Ogün CO, Ozerbil O, Ogün TC, Ugurlu H. Gabapentin is a first line drug for the treatment of neuropathic pain in spinal cord injury. Spine (Phila Pa 1976) 2004; 29: 74351.

41. Siddall PJ, Cousins MJ, Otte A, Griesing T, Chambers R, Murphy TK. Pregabalin in central neuropathic pain associated with spinal cord injury: a placebo-controlled trial. Neurology 2006; 67: 1792-800.

42. Rintala DH, Holmes SA, Courtade D, Fiess RN, Tastard LV, Loubser PG. Comparison of the effectiveness of amitriptyline and gabapentin on chronic neuropathic pain in persons with spinal cord injury. Arch Phys Med Rehabil 2007; 88: 1547-60.

43. Vranken JH, Dijkgraaf MG, Kruis MR, van der Vegt MH, Hollmann MW, Heesen M. Pregabalin in patients with central neuropathic pain: a randomized, double-blind, placebocontrolled trial of a flexible-dose regimen. Pain 2008; 136 : 150-7.

44. Cardenas DD, Nieshoff EC, Suda K, Goto S, Sanin L, Kaneko T, et al. A randomized trial of pregabalin in patients with neuropathic pain due to spinal cord injury. Neurology 2013; 80: 533-9.

45. Kaydok E, Levendoglu F, Ozerbil MO, Karahan AY. Comparison of the efficacy of gabapentin and pregabalin for neuropathic pain in patients with spinal cord injury: a crossover study. Acta Med Mediterranea 2014; 30: 1343.

46. Yilmaz B, Yaşar E, Köroğlu Omaç Ö, Göktepe AS, Tan AK. Gabapentin vs. pregabalin for the treatment of neuropathic pain in patients with spinal cord injury: a crossover study. Turk J Phys Med Rehab 2014; 61: 1-5.

47. Ghosh AK, Ghosh A, Kundu A, Das AK, Bhattacharya KB. Comparative study of efficacy and safety of pregabalin and gabapentin in neuropathic pain. Asian J Pharm Life Sci 2012; 2: 64-71.

48. Donegan S, Williamson P, Gamble C, Tudur-Smith C. Indirect comparisons: a review of reporting and methodological 
quality. PLoS One 2010; 5: el1054.

49. Dworkin RH, O'Connor AB, Backonja M, Farrar JT, Finnerup NB, Jensen TS, et al. Pharmacologic management of neuropathic pain: evidence-based recommendations. Pain 2007; 132: 237-51.

50. Putzke JD, Richards JS, Kezar L, Hicken BL, Ness TJ. Longterm use of gabapentin for treatment of pain after traumatic spinal cord injury. Clin J Pain 2002; 18: 116-21.

51. To TP, Lim TC, Hill ST, Frauman AG, Cooper N, Kirsa SW, et al. Gabapentin for neuropathic pain following spinal cord injury. Spinal Cord 2002; 40: 282-5.

52. Ahn SH, Park HW, Lee BS, Moon HW, Jang SH, Sakong J, et al. Gabapentin effect on neuropathic pain compared among patients with spinal cord injury and different durations of symptoms. Spine (Phila Pa 1976) 2003; 28: 341-6.

53. Song F, Loke YK, Walsh T, Glenny AM, Eastwood AJ, Altman DG. Methodological problems in the use of indirect comparisons for evaluating healthcare interventions: survey of published systematic reviews. BMJ 2009; 338: b1147.

54. Onouchi K, Koga H, Yokoyama K, Yoshiyama T. An openlabel, long-term study examining the safety and tolerability of pregabalin in Japanese patients with central neuropathic pain. J Pain Res 2014; 7: 439-47. 